\title{
Article \\ Occurrence of gastrointestinal (GI) parasites in Bengal Tiger and African Lion of Bangabandhu Sheikh Mujib Safari Park, Gazipur, Dhaka
}

\author{
Fahmida Tasnim Liza*, Mandira Mukutmoni and Aleya Begum \\ Department of Zoology, University of Dhaka, Dhaka 1000, Bangladesh \\ *Corresponding author: Fahmida Tasnim Liza, Department of Zoology, University of Dhaka, Dhaka 1000, \\ Bangladesh. E-mail: fahmida_2428@yahoo.com
}

Received: 30 March 2020/Accepted: 27 April 2020/ Published: 30 April 2020

\begin{abstract}
Forty-two fresh fecal samples from the Bengal tigers $(n=30)$ and African lions $(n=12)$ were collected during March 2018 to July 2018 from Bangabandhu Sheikh Mujib Safari Park, Gazipur, Dhaka. The fecal samples were processed using formol-ether concentration technique. A total of six types of parasites (egg/ cyst) were observed viz.; one protozoan (Coccidia spp.), two cestodes (Hymenolepis spp., and Diphyllobothrium spp.) and three nematodes (Ascaris spp., Toxocara spp. and hookworms). No trematodes were found during the study. Occurrence of gastrointestinal (hereafter GI) parasites recorded in tigers was $90 \%(\mathrm{n}=27 / 30)$ and lions was $100 \%(\mathrm{n}=12 / 12)$. The highest prevalence was of Coccidia spp. (85.71\%) followed by Diphyllobothrium spp. (42.86\%), Hymenolepis spp. (28.57\%), Ascaris spp. (21.43\%), Toxocara spp. (14.29\%) and hookworms (14.29\%). The prevalence of protozoans $(85.71 \%)$ was higher than that of helminths $(78.57 \%)$ in the hosts. On the basis of intensity of parasites, male carnivores were more susceptible to infection than females. The intensity of infection was higher in young ones as compared to adults.
\end{abstract}

Keywords: gastrointestinal parasites; fecal; captive; carnivores; felids

\begin{abstract}
1. Introduction
Zoological gardens play a significant role in the advancement of animal biodiversity by guarding endangered species (Kelly and English, 1997). But in captivity, the problem of parasitic infections in animals can worsen and pose a serious threat (Muoria et al., 2005). Parasitic infections are not only responsible for the morbidities of animals but heavier infections may actually be fatal (Chhabra and Pathak, 2013). In their natural habitat felids range over large areas, have low parasitic exposure and consequently low genetic resistance against parasitic infections (Raja et al., 2014). Since animals are kept in confined areas, parasitic diseases constitute one of the major problems in zoological gardens around the world due to high environmental contamination (Rao and Acharjyo, 1984).

Studies on parasitic infection of wildlife are still in first phase in Bangladesh with very few systematic studies. But the data are still on the base line. A few workers have recorded incidence of parasites in captive wild animals (Shrikhande et al., 2008). The present study is designed to investigate the gastrointestinal parasitic prevalence, intensity and influence of sex and age on parasitic prevalence and intensity in Bengal tigers and African lions of Bangabandhu Sheikh Mujib Safari Park, Gazipur, Dhaka.
\end{abstract}

\section{Materials and Methods}

\subsection{Study sites}

Bangabandhu Sheikh Mujib Safari Park, Gazipur, Dhaka $\left(24^{\circ} 10^{\prime} 12^{\prime \prime} \mathrm{N}, 90^{\circ} 23^{\prime} 48^{\prime \prime} \mathrm{E}\right)$ was chosen as study area for the collection of fecal samples from the host animals, Bengal tigers and African lions with the permission of the respective area's authority. The park is divided into five major sections- the Core Safari, Safari Kingdom, Biodiversity Park, Extensive Asian Safari Park and Bangabandhu Square. The Core Safari contains the 
carnivores like tigers, lions and bears, fishing cats, common palm civets etc. The cage of carnivores is square shaped and surrounded by iron grill. The floor is made of concrete. Water supply system is available inside every cage. The carnivores roam in a vast open space from $10 \mathrm{am}$ to $4-5 \mathrm{pm}$ in the afternoon which is similar to their native wild environment. Five-kilogram beef (six days in a week) and the other day, one rabbit is supplied as food for the Bengal tigers and African lions.

\subsection{Sample size}

A total of forty-two freshly defecated fecal samples of Bengal tiger (Panthera tigris) and African lion (Panthera leo leo) were collected. Thirty fecal samples were from Bengal tiger, among them nine samples were collected from males and twenty-one were from females. Twelve fecal samples were collected from male African lion. Age below or equal to five (Age $\leq 5$ ) years; was considered as age group A ( 21 fecal samples from Bengal tiger) and age below or equal to ten years but older than five $(5<$ Age $\leq 10)$ years; was considered as age group B $(9$ fecal samples from Bengal tiger and 12 samples from African lion).

\subsection{Collection and preservation of samples}

Fecal sample from individual animal were collected during March 2018 to July 2018 with the assistance of care taker of individual cage. Fecal samples were placed in a polythene bag containing $10 \%$ formalin. Each sample was marked according to species name, sex and age. Samples were examined at the Parasitology Laboratory, Department of Zoology, University of Dhaka.

\subsection{Coprological examination and data analysis}

The samples were processed by Formol-Ether Concentration Technique (Cheesebrough, 1987). Eggs and cysts observed under the microscope were identified following Chatterjee (1980), Cheng (1997), Soulsby (1982) and Schmidt and Roberts (1996). The number of eggs per gram (EPG) and cysts per gram (CPG) and prevalence of parasites were calculated following Margolis et al. (1982). Differences between the intensities was expressed using the standard deviation.

\section{Results and Discussion}

During the present study period, six different gastrointestinal parasites were observed of which, one protozoan (Coccidia spp.), two cestodes (Hymenolepis spp., and Diphyllobothrium spp.) and three nematodes (Ascaris spp., Toxocara spp. and hookworms) were identified. The most common and only protozoan parasite found in the present study on captive felids was Coccidia spp. All the male tigers and lions were found positive for at least one type of parasite (100\%) followed by female tigers (85.71\%) (Figure 1). Coccidia spp. (100\%), Toxocara spp. (33.33\%) and Hymenolepis spp. (33.33\%) were found in male tigers; while the female tigers were infected with all the six types of GI parasites- Coccidia spp. (71.43\%), Diphyllobothrium spp. (42.85\%), Hymenolepis spp. (28.57\%), Toxocara spp. (14.29\%), Ascaris spp. (14.29\%) and hookworms (14.29\%) (Table 1). In African male lions, all were found to be infected with Coccidia spp. (100\%) followed by Hymenolepis spp. (50\%), Diphyllobothrium spp. (50\%), Ascaris spp. (50\%) and hookworms (25\%) (Table 5). Coccidia spp. showed the higher intensity male tigers $(6.67 \pm 7.76)$ than in the female tigers $(4.8 \pm 4.61)$ (Table 2$)$. Toxocara spp. displayed the lowest intensity in male tigers $(2 \pm 1)$ and Ascaris spp. and hookworms in female tigers

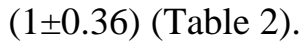

Among the samples collected from tigers of age group A $(n=15)$ and age group $B(n=15)$, the occurrence of parasitic infestation was $100 \%(15 / 15)$ and $80 \%$ (12/15) respectively (Figure 2). Coccidia spp. (100\%), Diphyllobothrium spp. (60\%), Hymenolepis spp. (20\%), Ascaris spp. (20\%) and hookworms (20\%) were found in tigers of age group A; however, the adult tigers of age group B were infected with Coccidia spp. (60\%), Toxocara spp. (40\%), Hymenolepis spp. (20\%) and Diphyllobothrium spp. (20\%) (Table 3). The lions of age group B were found to be infected with Coccidia spp. (100\%), Hymenolepis spp. (50\%), Diphyllobothrium spp. (50\%), Ascaris spp. (50\%) and hookworms (25\%) (Table 5); which is similar with the findings of tigers of age group A. In adult lions, the intensity of Coccidia spp. (27.25 \pm 12.91$)$ (Table 5) was much higher than in tigers of age group A $(5 \pm 4.68)$ and age group B $(6.33 \pm 6.85)$ (Table 4$)$.

In the present study, the prevalence of protozoans was observed to be higher than helminths. It may be due to different strategies of anthelmintic drug administration. Anthelmintic drugs are used in Safari Park animals at an interval of three months. The carnivores of Safari Park showed high protozoan infestation as they live in both outdoor open enclosure and cage. Another reason of high prevalence of protozoans could be the temperature. The appropriate temperature for successful oocyst sporulation is $4-37^{\circ} \mathrm{C}$ and optimal is at $29^{\circ} \mathrm{C}$ (Price et al., 
2014). All the samples were collected in hot summer days which were suitable for coccidian growth. Different species of Coccidian were found in captive carnivores at different Indian zoos, such as- MC Zoological Park (Singh et al., 2006), Nandankanan Zoo (Mahali et al., 2010) and Kerala Zoo (Ravindran et al., 2011).

No trematodes were found in the present study. The cause behind the absence of digenetic trematode parasites in captive wild carnivores could be explained by the complexity of the life cycle of these helminths, requiring at least one intermediate host (a gastropod mollusc) to evolve which is not usually present in the habitat of these carnivores kept in captive condition.

Patton and Rabinowitz (1994) found the cestode parasite belonging to families' like- Taeniidae, Hymenolepididae and genus such as- Toxocara spp., Isospora spp. (Coccidian) in a coprological survey conducted among wild felids in Thailand. Different Diphyllobothrium spp. were found in the study of Acharjyo, (2004) recorded from Indian wild carnivores which is also observed in the present study. Kolapo and Jegede (2017) found that Toxocara spp., Ancylostoma spp., Ascaris spp. and Coccidia spp. were the major intestinal parasites affecting the carnivores in University of Ilorin Zoological Garden, Nigeria.

In present study, comparing the male and female of Bengal tigers present in safari park, it was found that the prevalence rate was higher in males $(100 \%)$ than in females $(85.71 \%)$ and the intensity of parasites was varied. On the other hand, the male lions (12/12) also showed $100 \%$ infection rates.

According to Habig et al. (2018), there is a key difference between the sexes in immunity, life history strategies and behavior that may interact with the parasite exposure and susceptibility. Males tend to have weaker immunity than females and suffer disproportionately from parasitism and disease (Zuk and McKean, 1996; Nunn et al., 2009). Again, according to Aguilar and Mungu1'a-Steyer (2013), as the investment in parasite defense is energetically costly, mating effort should be traded off against parasite defense but in most mating systems males invest more in mating effort which would stand to reason that there would be a male sex-bias in parasitism.

In the present study, among two age groups of tigers, the infestation was higher in infant age group A than in the adult age group B. Comparison could not be done in case of lions as all the lion belonged to age group B which means adult. Host age is one of the most striking differences among hosts within most populations, but there is very little data on how age-dependent effects impact ecological and evolutionary dynamics of both the host and the parasite (Izhar and Ben-Ami, 2015). Children and the elderly individuals are the most disposed to parasitic diseases, developing severe forms of infection and suffering disproportionately high mortality rates compared to intermediate age groups (Simon et al., 2015). But the age wise prevalence and intensity of parasites also vary according to host species, habitat, predatory behavior etc.

The wild captive carnivores need to be screened constantly as they are critical to handle. An improved control plan should implicate supplementary targeted approach to manage parasites effectively limiting the pathogenic species by systematic fecal examination along with administration of anticipated worm treatment at regular intervals. The optimization of husbandry, prophylaxis and therapeutic practice to the type of parasitic treatment should be taken in order to prevent a possible failure to the survival of captive wild carnivore animals and preserve their aesthetic, recreational, conservational and educational purposes.

Table 1. Sex specific prevalence of GI parasites in Bengal tiger.

\begin{tabular}{lllllll}
\hline Parasites & \multicolumn{3}{c}{ No. of positive samples (No. of samples } & & Prevalence (\%) \\
& \multicolumn{3}{c}{ examined) } \\
\cline { 2 - 7 } & Male & Female & Total & Male & Female & Total \\
\hline Coccidia spp. & $9(9)$ & $15(21)$ & $24(30)$ & 100 & 71.43 & 80 \\
\hline Toxocara spp. & $3(9)$ & $3(21)$ & $6(30)$ & 33.33 & 14.29 & 20 \\
\hline Hymenolepis spp. & $0(9)$ & $6(21)$ & $6(30)$ & - & 28.57 & 20 \\
\hline Diphyllobothrium spp. & $3(9)$ & $9(21)$ & $12(30)$ & 33.33 & 42.85 & 40 \\
\hline Ascaris spp. & $0(9)$ & $3(21)$ & $3(30)$ & - & 14.29 & 10 \\
\hline Hookworms & $0(9)$ & $3(21)$ & $3(30)$ & - & 14.29 & 10 \\
\hline
\end{tabular}


Table 2. Sex specific intensities of GI parasites in Bengal tiger.

\begin{tabular}{lllll}
\hline Parasite & \multicolumn{2}{c}{ Bengal tiger (male) } & \multicolumn{2}{c}{ Bengal tiger (female) } \\
\cline { 2 - 5 } & EPG/CPG & Intensity \pm SD & EPG/CPG & Intensity \pm SD \\
\hline Coccidia spp. & 60 & $6.67 \pm 7.76$ & 72 & $4.8 \pm 4.61$ \\
\hline Toxocara spp. & 6 & $2 \pm 1$ & 15 & $5 \pm 1.79$ \\
\hline Hymenolepis spp. & - & - & 6 & $1 \pm 0.46$ \\
\hline Diphyllobothrium spp. & 15 & $5 \pm 2.5$ & 57 & $6.33 \pm 3.32$ \\
\hline Ascaris spp. & 0 & - & 3 & $1 \pm 0.36$ \\
\hline Hookworms & 0 & - & 3 & $1 \pm 0.36$ \\
\hline
\end{tabular}

Table 3. Age specific prevalence of GI parasites in Bengal tiger.

\begin{tabular}{lllllll}
\hline \multirow{2}{*}{ Parasites } & \multicolumn{2}{c}{ No. of positive samples (No. of samples examined) } & \multicolumn{3}{c}{ Prevalence (\%) } \\
\cline { 2 - 7 } & Group A & Group B & Total & Group A & Group B & Total \\
\hline Coccidia spp. & $15(15)$ & $9(15)$ & $24(30)$ & 100 & 60 & 80 \\
\hline Toxocara spp. & $0(15)$ & $6(15)$ & $6(30)$ & 0 & 40 & 20 \\
\hline Hymenolepis spp. & $3(15)$ & $3(15)$ & $6(30)$ & 20 & 20 & 20 \\
\hline Diphyllobothrium spp. & $9(15)$ & $3(15)$ & $12(30)$ & 60 & 20 & 40 \\
\hline Ascaris spp. & $3(15)$ & $0(15)$ & $3(30)$ & 20 & 0 & 10 \\
\hline Hookworms & $3(15)$ & $0(15)$ & $3(30)$ & 20 & 0 & 10 \\
\hline
\end{tabular}

Table 4. Age specific intensities of GI parasites in Bengal tiger.

\begin{tabular}{|c|c|c|c|c|}
\hline \multirow[t]{2}{*}{ Parasites } & \multicolumn{2}{|r|}{ Group A } & \multicolumn{2}{|r|}{ Group B } \\
\hline & EPG/CPG & Intensity \pm SD & EPG/CPG & Intensity \pm SD \\
\hline Coccidia spp. & 75 & $5 \pm 4.68$ & 57 & $6.33 \pm 6.85$ \\
\hline Toxocara spp. & 0 & - & 21 & $3.5 \pm 2.03$ \\
\hline Hymenolepis spp. & 3 & $1 \pm 0.41$ & 3 & $1 \pm 0.41$ \\
\hline Diphyllobothrium spp. & 57 & $6.33 \pm 3.36$ & 15 & $5 \pm 2.07$ \\
\hline Ascaris spp. & 3 & $1 \pm 0.41$ & 0 & - \\
\hline Hookworms & 3 & $1 \pm 0.41$ & 0 & - \\
\hline
\end{tabular}

Table 5. Occurrence of GI parasites in African lion (All male; and all belong to age group B).

\begin{tabular}{lllll}
\hline Parasites & $\begin{array}{l}\text { No. of positive samples } \\
\text { of samples examined) }\end{array}$ & Prevalence (\%) & $\begin{array}{l}\text { EPG/ } \\
\text { CPG }\end{array}$ & Intensity \pm SD \\
\hline Coccidia spp. & $12(12)$ & 100 & 327 & $27.25 \pm 12.91$ \\
\hline Hymenolepis spp. & $6(12)$ & 50 & 6 & $1 \pm 0.52$ \\
\hline Diphyllobothrium spp. & $6(12)$ & 50 & 57 & $9.5 \pm 5.08$ \\
\hline Ascaris spp. & $6(12)$ & 50 & 6 & $1 \pm 0.52$ \\
\hline Hookworms & $3(12)$ & 25 & 3 & $1 \pm 0.45$ \\
\hline
\end{tabular}

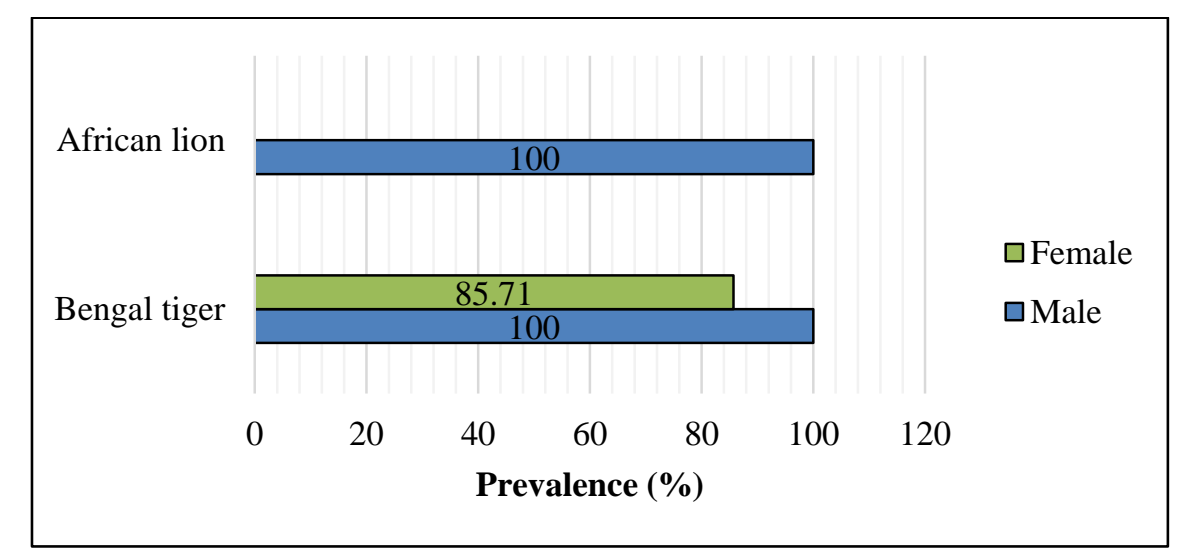

Figure 1. Sex specific occurrence of GI parasites in Bengal tiger and African lion. 


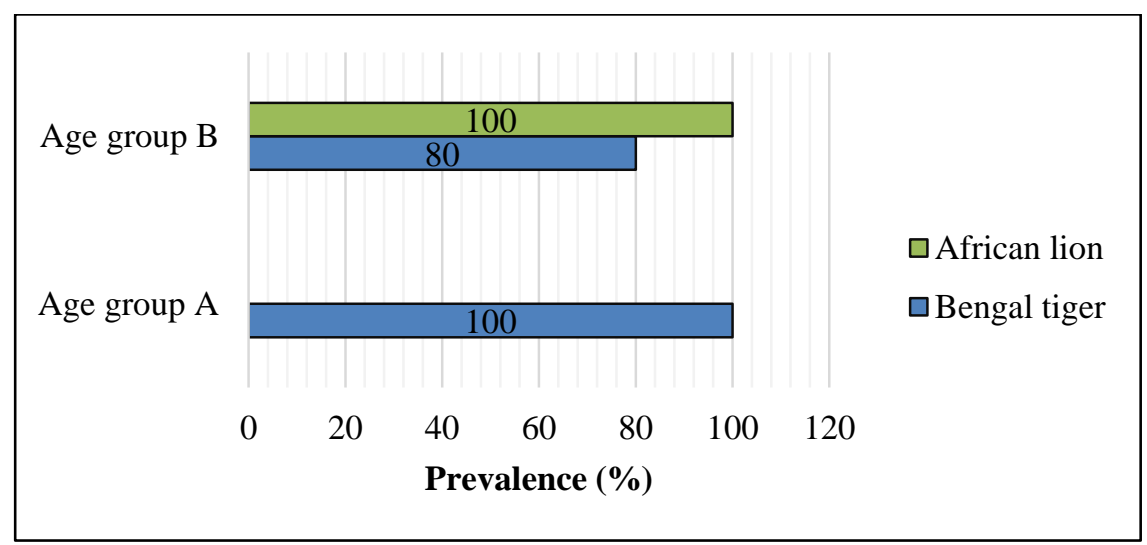

Figure 2. Age specific occurrence of GI parasites in Bengal tiger and African lion.

\section{Acknowledgements}

The authors are very grateful to the Forest Department of Bangladesh for permitting and providing required accessibilities; and Ministry of Science and Technology, Government of Bangladesh for giving National Science and Technology Fellowship to conduct this research work. Special thanks to the following persons who have helped in the study; Mohammad Ullah Khan (Assistant Conservator of Forests), Mohammad Samsul Azam (Project Director), Md. Motaleb Hossain (Officer in Charge) and Dr. Md. Nizam Uddin Chowdhury (Assistant Veterinary Surgeon) of Bangabandhu Sheikh Mujib Safari Park, Gazipur.

\section{Conflicts of interest}

None to declare.

\section{References}

Acharjyo LN, 2004. Helminthiasis in captive wild carnivores and its control in India. Zoos' Print, 19: 15401543.

Chatterjee KD, 1980. Parasitology. Chattergic Medical publishers Calcutta. pp. 208-211.

Cheesbrough M, 1987. Introduction to Parasitology. Cambridge University Press. pp. 209-213.

Chhabra MB and KML Pathak, 2013. Parasites and parasitic diseases of wildlife in India. 2. Carnivores and birds. Ind. J. Anim. Sci., 83: 567-578.

Córdoba-Aguilar A. and R. Munguía-Steyer, 2013. The Sicker Sex: Understanding Male Biases in Parasitic Infection, Resource Allocation and Fitness. PLoS One, 8: e76246.

Habig B, MM Doellman, K Woods, J Olansen and EA Archie, 2018. Social status and parasitism in male and female vertebrates: a meta-analysis. Sci. Rep., 8: 3629.

Izhar R and F Ben-Ami, 2015. Host age modulates parasite infectivity, virulence and reproduction. J. Anim. Ecol., 84: 1018-1028.

Kelly JD and AW English, 1997. Conservation biology and the preservation of biodiversity in Australia: A role for zoos and the veterinary profession. Aus. Vet. J., 75: 568-574.

Kolapo TU and OH Jegede, 2017. A Survey of Gastrointestinal Parasites of Captive Animals at the University of Ilorin Zoological Garden. Vom J. Vet. Sci., 12: 17-27.

Mahali AK, DN Panda, MR Panda, BN Mohanty and B Sahoo, 2010. Incidence and seasonal variation of gastro-intestinal parasitic infections in captive carnivores in Nandankanan Zoological Park, Orissa. J. Vet. Parasitol., 24: 111-115.

Margolis L, GW Esch, JC Holmes, AM Kuris and GA Schad, 1982. The Use of Ecological Terms in Parasitology (Report of an Ad Hoc Committee of the American Society of Parasitologists). J. Parasitol., 68: 131-133.

Muoria PK, P Muruthi, D Rubenstein, NO Oguge and E Munene, 2005. Cross-sectional survey of gastrointestinal parasites of Grevy's Zebras in southern Samburu, Kenya. Afr. J. Eco., 43: 392-395.

Nunn CL, Lindenfors P, Pursall ER and J Rolff, 2009. On sexual dimorphism in immune function. Philos. T. Roy. Soc. Lond. B. Biol. Sci., 364: 61-69.

Patton S and AR Rabinowitz, 1994. Parasites of Wild Felidae in Thailand: A Coprological Survey. J. Wildl. Dis., 30: 472-475. 
Price KR, MT Guerin and JR Barta, 2014. Success and failure: The role of relative humidity levels and environmental management in live Eimeria vaccination of cage-reared replacement layer pullets. J. Appl. Poult. Res., 23: 523-535.

Raja MMRU, AR Dey, N Begum, UK Kundu and FA Ashad, 2014. Coprological prevalence of gastrointestinal parasites in carnivores and small mammals at Dhaka Zoo, Bangladesh. J. Threat. Taxa., 6: 5574-5579.

Rao AT and LN Acharjyo, 1984. Diagnosis and classification of common diseases of captive animals at Nandankanan Zoo in Orissa (India). Ind. J. Anim. Health., 33: 147-152.

Ravindran R, KGA Kumar and VMA Gafoor, 2011. Parasitic infections in wild animals of Kerala. Zoos' Print, 26: 34.

Schmidt GD and LS Roberts, 1996. Foundations of Parasitology. Times Mirror Company. USA. pp. 7-670.

Shrikhande GB, AK Satpute, SS Zanzad and DK Maske, 2008. Helminth Parasites in Captive Wild Animals of Rajiv Gandhi Zoological Park. Vet. World, 1: 207.

Simon AK, GA Hollander and A Mcmichael, 2015. Evolution of the immune system in humans from infancy to old age. Proceedings of the Royal Society of London. Series B, Biological sciences 282: 20143085.

Singh P, MP Gupta, LD Singla, N Singh and DR Sharma, 2006. Prevalence and chemotherapy of gastrointestinal helminthic infections in wild carnivores of Mahendra Choudhury Zoolgoical Park, Punjab. J. Vet. Parasitol., 20: 17-23.

Soulsby EJL, 1982. Helminths, Arthopods and Protozoa of Domesticated Animals- $7^{\text {th }}$ Edition. Bailliere and Tindal, London. pp. 766-771.

Varadharajan A and A Kandasamy, 2000. A survey of gastro-intestinal parasites of wild animals in captivity in the V.O.C. Park and Mini Zoo, Coimbatore. Zoos' Print, 15: 257-258.

Zuk M. and KA Mckean, 1996. Sex differences in parasite infections: patterns and processes. Int. J. Parasitol., 26: 1009-1023. 